\title{
Identifying Stress
}

\section{Antonia Regina Ferreira Furegato}

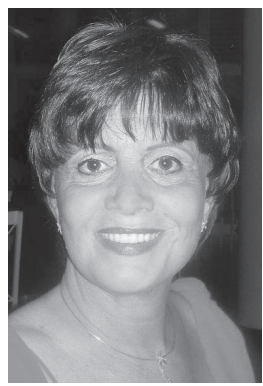

Concern for workers and for the conditions and functional structure of the workplace, as well as the dynamics of relationships among the various units of public and private institutions, is a subject of increasing interest in recent decades. In addition to the resources required to cope with natural difficulties given the nature of the work itself, these are elements present in the daily lives of workers.

In general, people try to find reasons to find satisfaction and feel self-realized in their work. When performing their roles, especially in adverse conditions, people's bodies try to keep balance using personal coping strategies. The body works constantly to maintain its stability and wellbeing using different strategies, despite adversity.

Anxiety is a warning sign, indicating a potential and/or imminent danger. It also, though, encourages the person to take measures to cope with stressful situations. Being under pressure or under a persistent stimulus, however, requires considerable physical, mental and emotional effort and may result in lower productivity, absences, and mixed feelings, culminating in organic, psychological and social consequences.

We are talking about occupational stress. Most stimuli triggering stress, even though unspecific, such as competitiveness, personal and economic safety, professional competence, and many other abstract threats, are completely real to people.

The Canadian endocrinologist Hans Selye (1907-1982) was the first to seriously study stress in the 1930s. He introduced concepts and a knowledge base, concretely showing the effects of stress on a person's body. He observed that different organisms present the same pattern of physiological response to sensorial or psychological stimuli with harmful effects on almost all the organs, tissues, or metabolic processes of people under stress. He identified three phases of stress: alarm, resistance, and exhaustion. Hence, a person affected by stress may need the help of his/her occupational environment itself or professional help ${ }^{(1)}$.

Because professionals in the health field deal directly with the lives of human beings, a high level of competence and responsibility are expected from their performance at work. Therefore, studies and actions designed to improve occupational conditions and the quality of life of workers are increasingly frequent ${ }^{(2-3)}$.

Likewise, investments are needed to identify situations that generate stress in the lives of people, with greater emphasis on situations arising among the elderly, adolescents, and those experiencing chronic disease and facing traumatic events such as surgery or circumstantial events such as maternity.

Research and studies are, directly or indirectly, improving nursing care provided in hospital services or in the primary healthcare network.

As observed in more recent nursing studies, health professionals seek to manage and implement humanized care, considering individual and collective projects and systemizing actions through a work process focused not only on technical aspects, but centrally concerned with the wellbeing and quality of life of people under care. 


\section{References}

1. Everly GS Jr, Lating JM. A clinical guide to the treatment of the human stress response. New York (USA): Springer; 2002. Book Series: The Plenum Series on Stress and Coping.

2. Alves PC, Neves VF, Coleta MFD, Oliveira AF. Evaluation of well-being at work among nursing professionals at a university hospital. Rev. Latino-Am. Enfermagem. 2012;20(4):701-9.

3. Ribeiro RP, Martins JT, Marziale MHP, Robazzi MLCC. Work-related illness in nursing: an integrative review. Rev EsC Enferm USP. 2012;46(2):495-504.

Antonia Regina Ferreira Furegato is Associate Editor of the Latin American Journal of Nursing, and Full Professor of the Escola de Enfermagem de Ribeirão Preto, Universidade de São Paulo, WHO Collaborating Centre for Nursing Research Development, Brazil, e-mail: furegato@eerp.usp.br. 